\title{
Meio século de Primavera silenciosa: um livro que mudou o mundo
}

\section{Half Century of Silent Spring: \\ a Book that Changed the World}

\author{
Ramón Stock BONZI*
}

\begin{abstract}
RESUMO
O ensaio visa investigar como a obra Primavera silenciosa, de Rachel Carson, tornou-se o livro fundador do movimento ambientalista moderno. Lançada em 1962, a obra é um alerta para os perigos do uso indiscriminado de pesticidas. Embora hoje seja presença obrigatória na bibliografia de referência de disciplinas voltadas ao estudo do meio ambiente, à época de seu lançamento a obra foi duramente combatida e sua autora, desacreditada. Este trabalho procura entender como um livro que destoava tão fortemente do senso comum pôde conquistar legitimidade e transformar-se em um dos produtos culturais mais importantes de nossa época.
\end{abstract}

Palavras-chave: meio ambiente; ecologia; pesticida; ambientalismo; paisagem.

\begin{abstract}
The essay aims at investigating how the work Silent Spring, by Rachel Carson, became the founding book of the new environmental movement. Launched in 1962, the work is a warning against the dangers of indiscriminate use of pesticides. Although it is today obligatory presence in the bibliography of disciplines aimed at studying the environment, at the time of its release the work was heavily fought against, and its author discredited. This paper seeks to understand how a book that so strongly clashed with common sense could gain legitimacy and become one of the most important cultural products of our time.
\end{abstract}

Keywords: environment; ecology; pesticide; environmentalism; landscape.

\footnotetext{
"Especialista em Meio Ambiente e Sociedade (FESPSP) e em Arquitetura da Paisagem (SENAC). Mestrando em Arquitetura e Urbanismo (FAUUSP). E-mail: rsb@usp.br
} 


\section{Introdução}

No verão de 1962, a revista New Yorker publicou três edições seguidas com trechos de Primavera silenciosa, quarto livro de Rachel Carson (1907-1964), obra que só seria lançada três meses depois, em setembro. Em linhas gerais, o livro explica como o uso desenfreado de pesticidas nos EUA alterava os processos celulares das plantas, reduzindo as populações de pequenos animais e colocando em risco a saúde humana.

Linda Lear, biógrafa da autora, conta que, após a publicação do primeiro trecho, "o alerta de Rachel Carson desencadeou um debate nacional sobre o uso de pesticidas químicos, a responsabilidade da ciência e os limites do progresso tecnológico" (LEAR, 2010, p. 11). A indústria química reagiu imediatamente, combatendo duramente a obra e entrando em campanha declarada para desacreditar a sua autora.

Passado pouco mais de meio século desses eventos, mudaram-se os atores, mas o debate permanece. E, embora a obra continue a inspirar uma ampla gama de militantes em defesa da natureza e seja presença obrigatória em qualquer histórico do movimento ambientalista, Primavera silenciosa continua sendo alvo de críticas.

Para alguns analistas, Carson "pode ter sido ocasionalmente imprecisa e alarmista" (MCCORMICK, 1992, p. 71), usando de "técnica de superdramatização calculada" (MADDOX apud MCCORMICK, 1992, p. 95), cometido deslizes estatísticos em sua tentativa de provar a existência de uma epidemia de leucemia (LOMBORG, 2002, p. 262) e de que sua exortação ao banimento do DDT pode ter sido precipitada, já que desencadeou o reaparecimento da malária em países do terceiro mundo (ANTUNES, 2008, p. 30).

Seja como for, é inegável que Primavera silenciosa foi um acontecimento comunicacional ${ }^{1}$ que mudou o mundo. A essa obra tem sido atribuída nada menos que a fundação do movimento ambientalista moderno. Como sabemos, não é pouca coisa.

Este ensaio procura entender como um livro que destoava tão fortemente do senso comum de uma época pôde conquistar legitimidade e transformar-se em um dos produtos culturais mais importantes da história recente.

Para tanto, iniciamos com a reconstituição do contexto histórico, procedimento fundamental para a identificação das características intrínsecas aos lugares de onde os discursos de Carson e da indústria química foram proferidos.

\section{O ambiente faz a alma}

Considerada a "mãe do ambientalismo", Rachel Carson foi uma bióloga marinha e escritora de mão cheia. Publicou a sua primeira história, A Battle in the Clouds, aos dez anos de idade. Segundo Lear (2010, p. 12), Carson desenvolveu a sua paixão pela natureza ainda cedo, na companhia de sua mãe, Maria, uma entusiasta do Movimento de Estudo da Natureza². Foi também com sua mãe que Carson desenvolveu o interesse pela literatura. Em 1925, Carson ingressou na Faculdade da Pensilvânia para Mulheres, com planos de se graduar em língua inglesa. No entanto, o incentivo de uma professora de zoologia a fez optar por biologia.

Após a graduação, Carson estudou no Laboratório de Biologia Marinha de Woods Hole e tornou-se mestre em zoologia pela Universidade John Hopkins, em 1932. Sem dinheiro para continuar os estudos, Carson passou a trabalhar como assistente de um laboratório na área de genética e, para garantir uma renda extra, começou a escrever artigos sobre a história natural da Baía de Chesapeake. Seus textos eram publicados pelo jornal

\footnotetext{
${ }^{1}$ Conceito elaborado pelo professor Dr. Ciro Marcondes Filho. Para o autor, “A descoberta de algo que não se sabia é o expor-se à 'violência', é o ato de a comunicação nos fazer pensar nas coisas, nos outros, em nós mesmos, na nossa vida. É algo de natureza absolutamente diferente do mero se informar e das falas triviais; trata-se de uma diferença radical de qualidade na participação em um acontecimento" (2009, p. 64). O acontecimento se dá nas relações, sejam elas entre pessoas ou entre pessoas e produtos culturais.

${ }^{2}$ Sob o lema de "study nature, not books", o Nature Study foi um movimento liderado por educadores norte-americanos, como Anna Botsford Comstock, Liberty Hyde Bailey, Louis Agassiz e Wilbur S. Jackman bastante popular no final do século XIX e começo do século XX. O movimento propunha reconciliar investigação científica com espiritualidade, experiências pessoais e interação com o mundo natural. E também era uma reação à industrialização. Disponível em: <http:// en.wikipedia.org/wiki/Nature_study>. Acesso em: 29/06/2013.
} 
Baltimore Sun sob a assinatura de "R. L. Carson" "a fim de que os leitores presumissem que o autor era homem e, assim, levassem seus conhecimentos científicos a sério" (LEAR, 2010, p. 14).

Em 1936, Carson conseguiu um emprego de meio período como redatora de rádio no Departamento Federal de Pesca. Um ano depois, foi designada para revisar os relatórios de outros cientistas. Em 1941, publicou seu primeiro livro, Sob o mar-vento (Under the Sea Wind), que recebeu boas críticas, mas que não se converteram em boas vendas.

Em The Gentle Subversive, Lytle (2007, p. 148), conta-se que foi em 1945 que Carson tomou conhecimento dos perigos do DDT. Ela editou uma pesquisa conduzida por seu chefe, Elmer Higgins, sobre como peixes estavam sendo afetados pelo pesticida. Preocupada, Carson chegou a mandar um artigo para a Reader's Digest, mas os editores o rejeitaram.

Em 1951, Carson lançou seu segundo livro: $O$ mar que nos cerca (The Sea Around Us), um apanhado de suas pesquisas oceanográficas que demorou dez anos para ser escrito. Uma versão condensada do livro foi publicada em série pela conceituada revista New Yorker, tornando Carson uma escritora famosa e premiada. Igual sucesso acompanhou a publicação de Beira-mar (The Edge of The Sea), em 1955. Rachel Carson tornou-se então a principal escritora de ciências dos Estados Unidos.

\section{Viver melhor através da química}

Mas o país estava passando por profundas mudanças... Em curso desde os anos 1940, a chamada
Revolução Verde $e^{3}$ continuava a desenvolver tecnologias, como sementes de alto rendimento, sistemas de irrigação, mecanização, fertilizantes, além de herbicidas, fungicidas e pesticidas químicos, a fim de aumentar a produção de alimentos.

O seu aparente sucesso, ao lado dos avanços da indústria farmacêutica, fez surgir nos anos 1950 a sensação de que "uma vida melhor através da química"4 era possível. E desejável. Os fazendeiros não precisavam mais adubar as suas terras com esterco ou perder tempo deixando-as em pousio. Agora, estavam à sua disposição práticos fertilizantes, que, na verdade, eram "sobras" da Segunda Guerra Mundial ${ }^{5}$, como também era o caso do DDT, usado em campo de batalha para combater os insetos transmissores de tifo, malária e febre amarela.

A confiança na "química" era tanta que crianças eram borrifadas com DDT a fim de combater pulgas e mosquitos. A publicidade exortava as donas de casa a se livrarem de baratas com a aplicação do pesticida. Um método seguro que podia ser aplicado até no quarto do bebế ${ }^{6}$. No nível governamental, entomologistas e agentes da saúde envolvidos em campanhas de controle da malária chegavam a comer colheradas de DDT para convencer a população de que a substância não representava perigo ${ }^{7}$. Os capitães da indústria ostentavam ainda o máximo reconhecimento científico: o Prêmio Nobel de Medicina de 1948 foi concedido ao químico Paul Müller por descobrir a utilidade do DDT como inseticida.

Tratava-se de uma visão de mundo - a de "viver melhor através da química" - que Primavera silenciosa iria pôr em xeque muito em breve.

\footnotetext{
${ }^{3}$ O programa teve início em 1946, quando o governo mexicano convidou a Fundação Rockfeller, dos EUA, a fazer estudos sobre a fragilidade de sua agricultura. A partir daí, cientistas criaram novas variedades de milho e trigo de alta produtividade, que fizeram o México aumentar de forma vertiginosa sua produção. Essas sementes foram, em seguida, introduzidas e cultivadas em outros países. Disponível em: <http://planetasustentavel.abril.com.br/noticia/atitude/conteudo_244070. shtml>. Acesso em: 29/06/2013

${ }^{4}$ Um bom exemplo da força dessa ideia é o slogan da DuPont, "Better Things for Better Living... Through Chemistry", que valeu de 1935 até 1982. Disponível em: <http://en.wikipedia.org/wiki/Better_Living_Through_Chemistry>. Acesso em: 29/06/2013.

${ }_{5}^{5}$ Da amônia podem-se obter nitritos e nitratos, essenciais tanto para a fabricação de fertilizantes nitrogenados quanto explosivos. Vários pesticidas e herbicidas foram desenvolvidos com fins militares e amplamente utilizados nas Guerras Mundiais como armas químicas.

A relação é histórica e bem conhecida: a Monsanto, por exemplo, produziu tanto herbicidas para uso agrícola quanto desfolhantes químicos, como o Agente Laranja, largamente utilizado na Guerra do Vietnã.

${ }^{6}$ Imagens que ilustram essas ações estão disponíveis em: <http://thesocietypages.org/socimages/2011/06/27/ddt-is-good-for-me-e-e/>. Acesso em: 29/06/2013.

${ }^{7}$ O vídeo "DDT: so safe you can eat it", trecho do filme "DDT Versus Malaria: A Successful Experiment in Malaria Control (1947)", está disponível em: <http:// www.youtube.com/watch?feature=player_embedded\&v=gtcXXbuR244>. Acesso em: 29/06/2013.
} 


\section{Chamado selvagem}

Embora acompanhasse com atenção os efeitos colaterais do uso indiscriminado de agrotóxicos ${ }^{8}$, escrever Primavera silenciosa não estava nos planos de Rachel Carson. Após Beira-mar, a autora escreveria um livro sobre a era atômica (QUARATIELLO, 2004, p. 81).

Aparentemente, Carson mudou de ideia ao receber a carta de Olga Owens Huckins, proprietária de um santuário da vida selvagem. Ela relatava a morte de uma grande quantidade de pássaros após a pulverização aérea de uma propriedade vizinha. Ela perguntava se Carson não conhecia alguém no governo capaz de parar os voos (QUARATIELLO, 2004, p. 86). Ao invés disso, Carson achou que seria mais eficaz escrever um artigo a respeito para um grande veículo de informação. ${ }^{9}$ A estratégia de Carson alinha-se perfeitamente à observação de Castells de que:

Noticiários de TV, rádio e jornais locais são o instrumento de divulgação dos ambientalistas, a ponto de existirem reclamações por parte dos políticos e das grandes corporações de que é a mídia, e não os ambientalistas, a grande responsável pela mobilização em torno da questão do meio ambiente (CASTELLS, 1999, p. 161).

A New Yorker manifestou interesse pelo artigo, mas, após algum tempo de pesquisa, Carson chegou à conclusão de que o assunto merecia um livro curto. Control of Nature seria escrito em três meses, em parceria com Edwin Diamond, o editor de ciências da
Newsweek. No entanto, seu parceiro desistiu e Carson teve uma série de problemas pessoais ${ }^{10}$, que acabaram adiando o lançamento do livro por quatro anos. Mas, em 1962, Primavera silenciosa saiu. E o mundo nunca mais foi o mesmo.

\section{Uma outra revolução verde}

A publicação do primeiro trecho, em 16 de junho de 1962, foi bombástica: a New Yorker recebeu uma quantidade de cartas muito maior do que qualquer outro artigo até então (QUARATIELLO, 2004, p. 105). E o livro tornou-se um best-seller assim que foi lançado.

Como explicar tal fenômeno? As boas vendas podem ser explicadas com base no fato de Carson já ser uma escritora aclamada. Mas nenhum dos livros anteriores de Carson provocou polêmica ou debate... E Primavera silenciosa estava mobilizando vários setores da sociedade, envolvendo até o presidente Kennedy ${ }^{11}$, que determinou que o Comitê de Consultoria Científica da Presidência estudasse a questão dos pesticidas (MCCORMICK, 1992, p. 70).

Como um livro lançado "num tempo de nova abundância e de intenso conformismo social" (LEAR, 2010, p. 11) e que criticava produtos que facilitavam a vida de milhões de pessoas pôde chamar a atenção e mudar tão profundamente a percepção de tanta gente, dando início a acontecimentos que levariam ao surgimento do movimento ambientalista?

Entendemos que, mesmo contrariando o senso comum da época, o "viver melhor através da química”, o

\footnotetext{
8 "In the fall of 1957, friends from the Washington chapter of the National Audubon Society told her about a U.S. Department of Agriculture (USDA) program to eradicate the fire ant from vast areas of southern farmlands and forests. [...] To fight this invasion, the USDA sprayers chose as their version of an entomological atomic bomb dieldrin and heptachlor, both chlorinated hydrocarbons far more lethal than DDT and serious risks to both wildlife and beneficial insects" (LYTLE, 2007, p. 122-123).

${ }^{9}$ É tentador creditar a Huckins um marco na sequência de acontecimentos comunicacionais que culminaram no grande debate público acerca do uso dos pesticidas, mas há polêmica sobre o peso que essa carta realmente teve.

Al Gore, por exemplo, declarou que "Silent Spring was born when [Carson] received a letter from a woman named Olga Huckins". Paul Brooks compartilha da opinião de Gore, enquanto Lear e Lytle acreditam que esse reconhecimento foi até certo ponto generosidade de Carson (LYTLE, 2007, p. 245-247).

${ }^{10}$ A sobrinha (Marjorie) morre em janeiro de 1957, deixando seu filho Roger órfão aos cinco anos de idade. O menino é adotado por Carson. Em dezembro de 1958, Maria, a mãe de Carson, morre. Em janeiro de 1960, Carson tem problemas respiratórios sérios e, quando está melhorando, em meados da primavera, é diagnosticada com câncer de mama. No final do mesmo ano, tem uma crise severa de artrite, que a impede de escrever por meses.

${ }^{11}$ At an August 29, 1962, White House press conference, a reporter asked President John F. Kennedy, "Mr. President, there appears to be a growing concern among scientists as to the possibility of dangerous long-range side effects from the use of DDT and other pesticides. Have you considered asking the Department of Agriculture or the Public Health Service to take a closer look at this?" Kennedy replied, "Yes, and I know they already are. I think particularly, of course, since Miss Carson's book, but they are examining the matter" (BROKE apud QUARATIELLO, 2004, p. 105-106).
} 
livro teve tamanho impacto porque trouxe o "novo", algo fundamental no processo comunicacional que, segundo Marcondes Filho, pode

[...] acontecer com um livro, um filme, um acontecimento que eu presenciei. Essas coisas podem me comunicar. Elas podem dizer-me algo pelo seu caráter de novidade, de estranheza, de inusitado, de inédito. É o novo que me muda; o conhecido apenas me reforça (MARCONDES FILHO apud ROSSETTI, 2009, p. 69).

No entanto, devemos levar em consideração que o mesmo autor afirma que "não nos interessa ouvir o lado da notícia que não é o nosso. Queremos, isso sim, notícias que fortaleçam nossas próprias posições, que as enrijeçam, que as alimentem, que as reforcem" (MARCONDES FILHO apud ROSSETTI, 2009, p. 64).

Sendo assim, por que as pessoas concederam a sua atenção para Primavera silenciosa? Entendemos que a resposta está na ligação que a autora estabeleceu entre o controle químico de insetos e a bomba atômica:

Juntamente com a possibilidade da extinção da humanidade por meio da guerra nuclear, o problema central da nossa idade se tornou, portanto, o da contaminação do meio ambiente total do Homem, por força do uso das referidas substâncias de incrível potência para produzir danos (CARSON, 1969, p. 18).

No auge da paranoia nuclear da Guerra Fria ${ }^{12}$, a sinalização "bomba atômica" era facilmente transformada em informação, porque capturava a atenção ${ }^{13}$. Carson trouxe também a noção de que produtos químicos poderiam agir sobre nós de maneira semelhante à da radiação:

Entre os ervicidas, existem alguns que são classificados como "mutagênicos", ou seja, como agentes capazes de modificar os genes, isto é, os materiais por meio dos quais se transmite a hereditariedade. Nós nos sentimos justamente estupefatos em presença dos efeitos genéticos das radiações; como poderemos, assim, ficar indiferentes aos mesmos efeitos produzidos por substâncias químicas que disseminamos amplamente pelo nosso ambiente? (CARSON, 1969, p. 47).

Ao estabelecer a semelhança entre ambos, Carson se utilizou de uma memória - o conhecimento que a população tinha sobre os efeitos nocivos da bomba atômica - usando, portanto, um esquema anterior já formado, o que, segundo Marcondes Filho (2004, p. 505), facilita o aprendizado. Primavera silenciosa continha, portanto, informação com grande potencial para gerar comunicação, o que entendemos ter ocorrido.

Neste sentido, a obra foi beneficiada por uma coincidência: pouco antes de seu lançamento, estabeleceu-se a relação entre o medicamento talidomida e a má-formação fetal. Lear relata que, ao ser questionada sobre o assunto - à época, uma verdadeira controvérsia nacional -, Carson fez uma "conexão óbvia" que ganhou as páginas do New York Post: "talidomida e pesticidas representam a nossa vontade de se apressar em usar algo novo, sem saber quais serão as consequências" (LEAR, 1997, p. 412) (tradução livre) ${ }^{14}$.

Desta maneira, bomba atômica e talidomida forneciam esquemas de aprendizado que facilitavam a apreensão das novas informações que Carson trazia ao conhecimento do grande público com seu Silent Spring.

\section{O império contra-ataca}

Quase imediatamente, a autora tornou-se alvo de ataques vindos do Departamento de Agricultura dos Estados Unidos (MCCORMICK, 1992, p. 71) e da indústria

\footnotetext{
${ }^{12}$ A crise dos mísseis em Cuba quase levou Estados Unidos e União Soviética a uma guerra nuclear em 1962.

${ }^{13}$ Para Marcondes Filho (2009, p. 63), "tudo sinaliza, não dá para não sinalizar. [...] Eu transformo sinais em informação quando me volto a eles, quando lhes dou atenção, quando lhes concedo minha curiosidade ou minha preocupação". Já a “[...] comunicação realiza-se no plano da interação entre duas pessoas, nos diálogos coletivos, onde esse novo tem chance de aparecer, onde o acontecimento provoca o pensamento, força-o, onde a incomunicabilidade é rompida e criam-se espaços de interpenetração. Mas ocorre igualmente nas formas sociais maiores de contato com objetos, especialmente com objetos culturais das produções televisivas, cinematográficas, teatrais, nos espetáculos de dança, das performances, nas instalações, a possibilidade de criação de situações similares, inclusive em ambientes de relacionamento virtual" (2009, p. 64).

14 "thalidomide and pesticides - they represent our willingness to rush ahead and use something new without knowing what the results are going to be" (CARSON apud LEAR, 1997, p. 412).
} 
de pesticidas, que gastou 250 mil dólares em "relações públicas" a fim de desqualificá-la (LEAR, 2010, p. 17).

Talvez o mais famoso crítico de Primavera silenciosa tenha sido o Dr. Robert White-Stevens, bioquímico e diretor-assistente da divisão de pesquisas agronômicas da American Cyanamid. Em um depoimento para The Silent Spring of Rachel Carson ${ }^{15}$, programa especial da CBS Reports exibido em abril de 1963, ele declarou:

As principais alegações feitas no livro da srta. Rachel Carson, "Primavera Silenciosa", são distorções grosseiras da verdade, sem suporte algum em evidências científicas ou em experiência prática de campo (WHITESTEVENS apud QUARATIELLO, 2004, p. 112). (tradução livre) $^{16}$.

É possível identificar no discurso uma tentativa clara de desqualificar a obra porque seu autor é uma mulher (o uso sarcástico de "miss", já que Carson tinha 55 anos) e também cientificamente, já que afirma que Carson distorceu dados. Carson seria então, na melhor das hipóteses, uma cientista menor, sem experiência de campo. Os biógrafos da autora revelam que também foram feitas tentativas de desqualificá-la devido ao fato de Carson não ter um doutorado. E por ela ser bióloga marinha e não bioquímica!

No nosso entender, o discurso espelha claramente o local de onde foi proferido: a indústria química dos anos 1950, terreno dominado por homens e por uma ciência altamente especializada, que valorizava resultados práticos e que considerava que outros saberes eram menores ou até mesmo desprezíveis.

Mais à frente, sem se dar ao trabalho de dar exemplos das "distorções ou da falta de evidências científicas" do livro, White-Stevens afirma:

A srta. Carson sustenta que o equilíbrio da natureza é a força principal na sobrevivência do Homem apesar de os químicos modernos, os biólogos modernos e os cientistas modernos acreditarem que o Homem está gradualmente controlando a natureza (WHITE-STEVENS apud QUARATIELLO, 2004, p. 112) (tradução livre) ${ }^{17}$.

No trecho acima, ao menosprezar a importância do equilíbrio da natureza para a sobrevivência do ser humano, o discurso de White-Stevens revela desprezo e/ ou ignorância em relação à Ecologia. O discurso também se revela antropocêntrico, ao afirmar que a maioria dos cientistas acredita que o "controle da natureza" é que será o responsável pela sobrevivência do ser humano, portanto, só concedendo valor à natureza na medida em que ela serve ao Homem. E, talvez, num ato falho - "modernos químicos, modernos biólogos e modernos cientistas" - revele ainda a hierarquia da indústria, com os químicos em lugar privilegiado.

O programa quase não foi ao ar. No último momento, patrocinadores cancelaram seus anúncios ${ }^{18}$.

\section{Da paisagem como legítima defesa}

Entendemos que a legitimidade do alerta de Carson (acerca dos perigos do uso de pesticidas) feito por meio de um veículo de informação de massa - a New Yorker- firmou-se quase instantaneamente, já que Castells, ao esmiuçar o processo de legitimação dos discursos, afirma que:

A legitimidade das questões levantadas pelos ambientalistas, diretamente relacionadas a valores humanistas apreciados pela maioria das pessoas, e muitas vezes distantes da política partidária, abriu caminho para que a mídia assumisse o papel de voz do povo, contribuindo para que sua própria legitimidade se firmasse (CASTELLS, 1999, p. 161-162).

\footnotetext{
${ }^{15}$ Trecho de The Silent Spring of Rachel Carson pode ser visto no documentário "Earth Days - Dia da Terra". Disponível em: < http://www.youtube.com/watch?v=GK-Xyc9Wo3Q>. Acesso em: 29/06/2013.

16 "The major claims of Miss Rachel Carson's book Silent Spring are gross distortions of the actual facts, completely unsupported by scientific experimental evidence and general practical experience in the field."

17 "Miss Carson maintains that the balance of nature is a major force in the survival of man whereas... the modern scientist believes that man is steadily controlling nature."

18 "Lehn \& Fink Products, the makers of Lysol, and two food manufacturers, Standard Brands and Ralston Purina, thought that the program would not be an appropriate one on which to promote their products" (QUARATIELLO, 2004, p. 112).
} 
Ao longo de Primavera silenciosa, são inúmeras as passagens em que Carson coloca-se como defensora de "valores humanistas apreciados pela maioria das pessoas": a sobrevivência da raça humana, a conservação e a preservação da natureza, o direito à qualidade de vida/saúde e até a defesa do símbolo nacional do país, a águia americana:

Como o papo-roxo, outra ave norte-americana parece estar na iminência da extinção. Trata-se do símbolo nacional dos Estados Unidos, a águia. [...] Os fatos sugerem que alguma coisa está atuando no meio ambiente próprio dessa águia - e que essa alguma coisa já lhe destruiu, virtualmente, a capacidade de reproduzir-se. O que essa coisa possa ser, não se sabe ainda: mas há alguma evidência de que os inseticidas são responsáveis também neste caso (CARSON, 1969, p. 127).

Em sintonia com o notório apreço norte-americano por paisagens ligadas à noção de "wilderness", vida natural/selvagem (DIEGUES, 2008, p. 26), que pode ser constatado na popularidade de parques nacionais como Yellowstone e Yosemite, Rachel Carson faz o alerta de que as paisagens que simbolizam a nação também estão ameaçadas. A autora dedica boa parte do capítulo 6 - "O Manto Verde da Terra"- para demonstrar essa tese:

Um dos exemplos mais trágicos do nosso impensado e insensato maltratar da paisagem pode ser visto nas plantações de artemísia do Oeste norte-americano, onde uma vasta campanha se encontra em curso, no sentido de se destruir essa planta e deixar em seu lugar os relvados das pradarias. Se jamais um empreendimento precisou ser esclarecido, com sentido de História e significação de paisagem, este é o empreendimento. Porque aqui a paisagem natural é eloquente; ela fala por si, das interações das forças que a criaram. As interações desenrolaram-se aos nossos olhos, como se fossem páginas de um livro aberto, nas quais podemos ler a razão pela qual a terra é o que é, e também a razão pela qual devemos preservar-lhe a integridade. Mas as páginas prosseguem sem ser lidas (CARSON, 1969, p. 74).

Ou ainda:
As margens das estradas do Maine constituem meramente um exemplo, embora particularmente desolador, para todos nós que nutrimos profundo amor para com a beleza do mencionado estado da União Norte-Americana, da insensata destruição que vai sendo praticada por aí adiante, em nome do controle das plantas arbustivas de beira de estrada, por todo o âmbito da nação (CARSON, 1969, p. 80).

Após construir a ideia de que a paisagem das "áreas selvagens" é, em última instância, a própria essência do que constitui a América, a autora parece antecipar em décadas o conceito de "desenvolvimento sustentável", demonstrando que a conservação da natureza não é necessariamente antagônica às atividades econômicas:

Agora, o cultivo científico e a destruição química das sebes e das ervas estão eliminando os derradeiros refúgios destes insetos polinizadores [...] tão essenciais à nossa agricultura $\mathrm{e}$, ademais, à nossa paisagem. [...] Pelo acerto do ritmo, exato e delicado, que é próprio da Natureza, o aparecimento de certa espécie de abelhas selvagens ocorre exatamente no dia da abertura da florada do salgueiro. Não há falta de homens que compreendam estas coisas; mas estes não são os homens que ordenam a inundação em massa, da paisagem, por substâncias químicas (CARSON, 1969, p. 83-84).

Alinhando-se a um desses "valores apreciados pela maioria das pessoas", a paisagem, Primavera silenciosa conquista mais um quinhão de legitimidade.

\section{Da ciência como legitimadora do discurso}

Ao trazer para a arena pública fortes evidências científicas de que o uso de pesticidas afeta os insetos polinizadores, prejudicando, portanto, os rendimentos econômicos provenientes da agricultura, Carson confere mais um valor à paisagem "selvagem", "natural". Ainda que há décadas tal paisagem seja considerada inútil pelos capitães da Revolução Verde, os atributos que Carson confere a esta paisagem têm o poder de metamorfoseá-la em paisagem produtiva. Carson se vale da noção de "serviços ambientais", expressão que só seria formal- 
mente cunhada em $1970^{19}$, como estratégia de defesa do meio ambiente.

Embora a indústria química continuasse com ferozes ataques à obra e à autora, seus esforços perderam boa parte da potência com a saída do parecer favorável do Comitê de Consultoria Científica da Presidência,em 15 de maio de 1963.

O relatório, observou Science, era "uma justificação bastante completa" de Silent Spring, Ao corroborar a tese de Carson [...] o relatório do comitê mudou a natureza do debate; ninguém mais podia negar que o problema existia (MCCORMICK, 1992, p. 70).

Com o parecer Use of Pesticides, Primavera silenciosa conquistou legitimidade indiscutível também na esfera científica. Podemos afirmar que esta legitimidade permanece, até hoje, praticamente intocada, mesmo com a divulgação de estudos científicos mais recentes sobre a questão dos agrotóxicos.

Vale registrar que a relação entre DDT e câncer em seres humanos nunca foi comprovada: a EPA (Environmental Protection Agency) estadunidense classificou o pesticida como provavelmente carcinogênico (probable human carcinogen). Mesmo assim, livro e clamor público levaram à proibição do DDT nos EUA em 1972. Além do DDT, outras onze substâncias tóxicas listadas em Primavera silenciosa foram proibidas ou sofreram restrições (MCCORMICK, 1992, p. 71).

Em 2006, uma reviravolta: a Organização Mundial da Saúde deu parecer favorável ao uso do DDT nos países africanos afetados pela malária, alegando que os benefícios de seu uso em ambientes fechados extrapolam largamente os riscos ambientais e à saúde humana. Ambientalistas, naturalmente, protestaram.

\section{Considerações finais}

Segundo Marcondes Filho, a comunicação resulta de um processo de interação entre pessoas ou entre uma pessoa e um produto cultural. Verificamos que isso aconteceu com Primavera silenciosa, já que se formou um amplo debate nacional em torno da obra. Das relações que as pessoas estabeleceram com o livro (e com suas derivações: matérias jornalísticas, entrevistas televisivas e também como assunto do cotidiano) deu-se o acontecimento, entendido aqui como energia transformadora que leva à mudança.

A formação de um movimento no sentido de restringir o uso de pesticidas e herbicidas demonstra claramente que as informações trazidas por Carson foram recebidas como novidade pelo público. Esta é a essência da COMUNICAÇÃO, segundo Marcondes Filho: descobrir algo que não se sabia antes.

A permanência da obra se deve muito mais ao que Primavera silenciosa trouxe de novo enquanto visão de mundo do que em termos de descobertas científicas. Seu poder comunicacional repousa na capacidade que a autora teve de retirar a questão dos "biocidas" da esfera técnico-científica para abordá-la na arena pública, evidenciando a necessidade de uma nova concepção civilizatória que não trate a Natureza como inimiga do Homem. Como sabemos, esta é uma ideia-chave do ambientalismo moderno.

Primavera silenciosa é, cada vez mais, uma obra fundamental para quem busca entender o nosso tempo. Ainda debatida, meio século depois de seu lançamento, é fonte de inspiração renovada para aqueles que procuram uma forma de se relacionar com o entorno.

No entanto, talvez outro grande legado ainda esteja por ser descoberto e estudado: Primavera silenciosa enquanto produto cultural que mudou o mundo. O presente trabalho foi a nossa tentativa de colaborar com algo nesse sentido.

\footnotetext{
${ }^{19}$ O termo foi lançado no relatório "Study of critical Environmental Problems (SCEP)", do MIT (Massachusetts Institute of Technology), e define como "serviços ambientais" o controle de pestes, polinização por insetos, pesca, regulação climática, retenção de solo, controle de cheias, formação de solos, ciclagem de matéria e composição da atmosfera.
} 


\section{Referências}

ANTUNES, Paulo de Bessa. Direito Ambiental. Rio de Janeiro: Lumen Juris, 2008.

CARSON, Rachel. Primavera silenciosa. São Paulo: Melhoramentos, 1969.

CASTELLS, Manuel. O "verdejar" do ser: o movimento ambientalista. In: . O poder da identidade. Rio de Janeiro:

Paz e Terra, 1999.

DIEGUES, Antonio Carlos. O mito moderno da natureza intocada. São Paulo: Hucitec, 2008.

EPA (Environmental Protection Agency - United States). DDT - A Brief History and Status. Disponível em: <http://www.epa. gov/pesticides/factsheets/chemicals/ddt-brief-history-status. $\mathrm{htm}>$. Acesso em: 29/06/2013.

LEAR, Linda. Rachel Carson:witness for nature. New York: Henry Holt and Company, 1997.

.Introdução. In: CARSON, Rachel. Primavera silenciosa. São Paulo: Gaia, 2010.
LOMBORG, Bjorn. O ambientalista cético: revelando a real situação do mundo. Rio de Janeiro: Elsevier, 2002.

LYTLE, Mark H. The gentle subversive: Rachel Carson, Silent Spring, and the rise of the environmental movement. New York: Oxford University Press, 2007.

MARCONDES FILHO, Ciro. A realidade dos meios de comunicação. In: . O escavador de silêncios: formas de construir e desconstruir a comunicação. São Paulo: Paulus, 2004.

Comunicação. In: MARCONDES FILHO, Ciro (Org.). Dicionário da Comunicação. São Paulo: Paulus, 2009.

MCCORMICK, John. Rumo ao paraíso: a história do movimento ambientalista. Rio de Janeiro: Relume-Dumará, 1992.

QUARATIELLO, Arlene Rodda. Rachel Carson: a biography. Westport: Greenwood Biographies, 2004.

ROSSETTI, Regina. Nova teoria da comunicação. Comunicação \& Inovação. São Caetano do Sul, 2009.

Recebido em 05 de março de 2013. Aceito em 01 de novembro de 2013. Publicado em dezembro de 2013. 